\title{
Overview of solutions and analysis of the ability to evaluate the performance parameters of unmanned aerial vehicles propulsion systems
}

\author{
Dominik Karpiński ${ }^{1, *}$, and Marta Galant ${ }^{1}$ \\ ${ }^{1}$ Poznan University of Technology, Faculty of Machines and Transport, ul. Piotrowo 3, 60-965 Poznan, Poland
}

\begin{abstract}
The aim of aircraft engines development is the propulsion which is characterized by high powerto-mass ratio. Therefore, the alternative solutions that provide the required power by the low weight propulsion are sought after. The main advantage of these solutions is improvement of environmental and economic properties. This paper presents the overview of solutions and studies conducted for the unmanned aerial vehicles propulsion. For the purposes of studies a test bench was prepared. Its enables the comparison of the propulsion operating parameters taking into account changes in the values of thrust and propulsion power. The summary includes a proposal to improve the environmental indicators of propulsion systems for unmanned aerial vehicles.
\end{abstract}

\section{Introduction}

As a result of the growing popularity of unmanned aircraft, these objects are used increasingly more often. Currently, unmanned aerial vehicles are used both for military and civilian purposes. A significant group of currently used UAVs are used as a part of a hobby. Furthermore, unmanned aerial vehicles are used in the activities of: monitoring disaster, geodetic and meteorological measurements, in search and rescue, forensic finding, aerial photography, inspection of power lines and pipelines, as well as forest fire detection and monitoring [1-4].

The main task of propulsion system for unmanned aerial vehicles is to provide the thrust needed for flight. Small UAVs mostly use lithium-polymer batteries (LiPo), while larger vehicles rely on conventional airplane engines. As a propulsion system for UAV piston, turbojet, turboshaft, electric and hybrid engines can be used. The type of used engine depends largely on the purpose of the UAV, e.g. as a pilotless target aircraft (high speed required), tactical recognition (high range and altitude), direct field recognition (low sound profile, low speed and altitude). However, the key issue is the reliability of the UAV. Research conducted by the US Department of Defense showed that most of the UAV malfunction was caused by power units and propulsion (38\%). Second cause were problems with flight control (Fig. 1). The other are problems with communication, human and ground problems and miscellaneous causes [5].

For commercial and military airplanes alike as well as flying platforms, mainly internal combustion engines are used as propulsion. However, despite such a high popularity of this type of drive, manufacturers are increasingly looking for alternative solutions, which combining an internal combustion engine with an electric motor or, for smaller aircraft (platforms), to completely replace ICE with electric drives. Electric engines compared to ICE are much less complicated to use and operate.

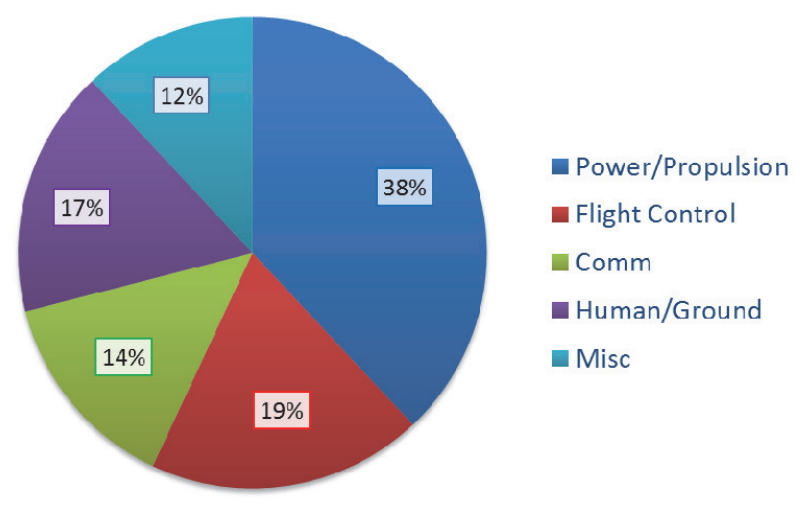

Fig. 1. Average sources of system failures for US Military UA fleet $[1,6]$.

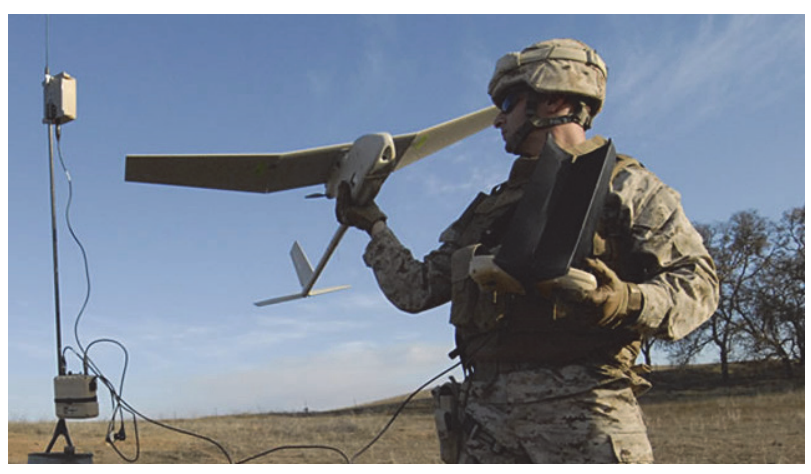

Fig. 2. Electrical drive application in RQ-11 Raven [6].

Corresponding author: dominik.p.karpinski@doctorate.put.poznan.pl 


\section{Prospects for the development of BPL propulsion units}

The UAV global military market is dominated by pioneers in the United States and Israel. The US held a $60 \%$ military-market share in 2006 [7]. It operated over 9000 UAVs in 2014. From 1985 to 2014, exported drones came predominantly from Israel $(60.7 \%)$ and the United States (23.9\%). Top importers were The United Kingdom (33.9\%) and India (13.2\%). The leading civil UAV companies are currently (Chinese) DJI with $\$ 500 \mathrm{~m}$ global sales, (French) Parrot with $\$ 110 \mathrm{~m}$ and (US) 3DRobotics with $\$ 21.6 \mathrm{~m}$ in 2014. As of March 2017, more than 770,000 civilian drones were registered with the U.S. FAA, though it is estimated more than 1.1 million have been sold in the United States alone [8, 9].

The introduction of new solutions to the aviation industry is a long term process involving advanced testing and certification procedures. This is due to the existing legislation, taking into account the highest standards of safety and reduce the negative impact of transport on the environment. The requirements imposed on manufacturers and unmanned aerial vehicles are mainly related to the improvement of their propulsion systems. The main goal of engine improvement is to increase economy by reducing service costs, reducing fuel consumption, and achieving the highest power-tomass ratio. Military and civil aviation also play an important role in protecting the environment, thus reducing the toxicity of exhaust gases and reducing noise level, but in the case of UAV this is less important [10]. Particularly important to the development of propulsion units is to reduce their weight without lowering the received thrust. This is achieved by the use of more and more modern construction materials. In the UAVs weighing more than $50 \mathrm{~kg}$ to reduce engine mass boralyn alloys are used. It is a material developed for nuclear rocket heads and used for the production of Formula 1 engine car hulls [1]. This is a relatively inexpensive composite made from aluminum reinforced by boron carbide, making its density comparable to that of pure aluminum. However, in terms of endurance boralyn is second to none. It surpasses titanium, aluminum and steel.

In aviation, security is a very important issue. It is defined as the sum of the reliability of equipment and people. Therefore, in unmanned platforms, redundancy and duplication of certain components and circuits will continue to apply. The UAVs are also equipped with electronics so that when a malfunction is detected, the mission is interrupted and the platform is returned to the starting area.

In the literature [11] one can find the prospect of development of the unmanned actuators towards the use of internal combustion engine with rotary piston or with horizontally-opposed cylinders (boxer type). The engine will be controlled by a digital circuit that will send information about its parameters to the operator in real time. The engine intake system should be equipped with de-icing and dust removal equipment. Care should also be taken to limit noise emission, infrared radiation and harmful exhaust emissions. Seems realistic production of the unmanned aircraft weighing over $50 \mathrm{~kg}$ driven by electric motors powered by fuel cells. This will virtually eliminate both the emission of harmful exhaust and the emission of noise [12].

The greatest opportunity for the development of propulsions for the UAV is seen in the use of hybrid drive system. The use of hybrid (ICE-electric) drive in Unmanned Aerial Platforms brings together the advantages of the internal combustion engine (high energy value of aviation fuel) and electric motor (high energy conversion efficiency) [13-16]. Due to the differences between the vehicle's drive cycle and the aircraft flight profile, it is not possible to directly translate the advantages of the hybrid system from road to air transport. The aircraft flight profile is characterized by significantly lower load variations, so that energy recuperation and slow motion phase cannot contribute to improving fuel efficiency. The energy requirement for the aircraft is the highest during the takeoff and climb phases (Fig. 3). This entails the use of conventional aircraft engines to achieve the desired startup power. However, the takeoff and climb phases represent only a few percent of the time in the aircraft flight profile, so the internal combustion engines use only about half of their maximum power. When using a hybrid drive, the role of engines differs depending on the requirements of the propulsion system performance. For example, during an climb phase, the aircraft uses the energy stored in the batteries and the internal combustion engine is an additional emergency drive. It is also possible to use reverse configuration, in which the electric drive acts as an auxiliary unit. In the phases of flight with the highest energy demand, the system draws energy from both engines. These advantages indicate the appropriateness of carrying out work on adaptation of the hybrid propulsion system in the aviation industry.

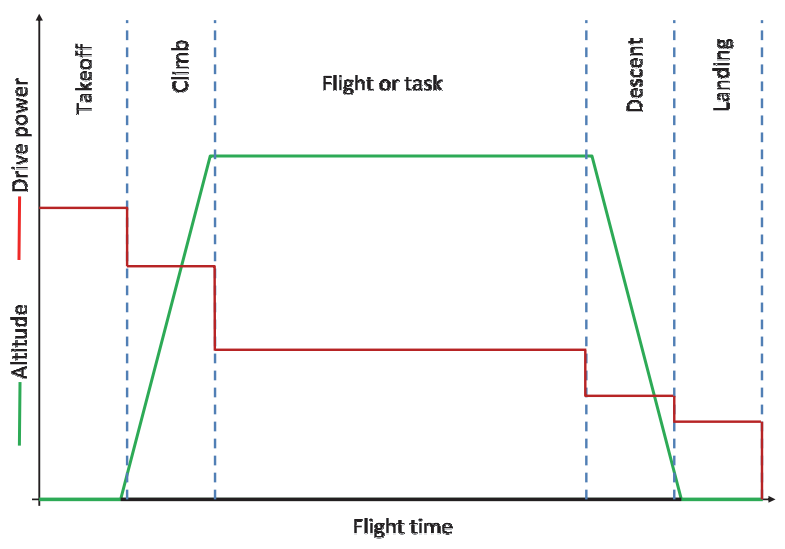

Fig. 3. Traditional aircraft flight profile.

The hybrid system intended for use in a flying object consists of five basic elements, of which there are distinguished: propeller as thrust generator, two power converters (combustion and electric engine), two power sources (hydrocarbon fuel and accumulators). The auxiliary components required for the operation of the drive system are the electric motor controller and the clutch. 
At the stage of development of the hybrid propulsion system designed to adapt to flying objects, should take into account many factors that affect their opportunities for further exploitation. These include: safety of applied solutions, operating range of the vehicle, criteria and restrictions for such propulsions. Selection of the propulsion system intended for use in aviation is conditioned by criteria such as weight, system efficiency, system complexity, exhaust and noise emissions, manufacturing and operating costs. The mass criterion largely translates into object performance and associated economic (fuel consumption, maximum takeoff mass), logistic (required takeoff and landing procedures) and environmental (exhaust and noise emissions) aspects [17]. Unmanned aerial vehicles require the lowest possible mass of the propulsion system. The technology available today allows the electric motor to be used as a propulsion or generator engine, which reduces the number of required conversion energy sources, and above all reduces the weight of the entire system.

At the time of designing a hybrid propulsion system, a significant factor is the area of application of the flying object and, in particular, its flight profile. The aircraft flight profile is the basis for determining the energy demand in the hybrid propulsion system. Knowledge of the amount of energy and the time required for the particular phase of flight is key information for determining the configuration and operating conditions of the propulsion system. The above-described aircraft flight profile is a contractual profile, which depending on the object application area may be subject to various modifications.

Among the potential benefits of using a hybrid propulsion system are the following: extended flight time, improved energy efficiency, reduced exhaust and noise emissions. In addition, the hybrid propulsion system enables the use of smaller displacement internal combustion engine operating at the speed range corresponding to its highest efficiency. The electric motor used in the propulsion system is a source of additional power, especially during acceleration or climb phase, and serves as a generator in case stabilized flight conditions.

\section{Research methodology}

Currently, the most commonly used electric motors for unmanned aerial vehicles are brushless AC motors These types of motors are characterized by high efficiency and ease of control and operation. In addition, the advantage of brushless AC motors is the large power to mass ratio as well as the ability to operate in a wide range of engine shaft speed. Due to the requirements for the unmanned aircraft propulsion system, the electric motor should be of small dimensions and low weight and as efficient as possible As a result, three-phase AC electric motor EMP N6354/13 (Fig. 4) was selected for the research. Engine technical specification is shown in Table 1. The external rotor was used to obtain high torque values at small dimensions in the engine.

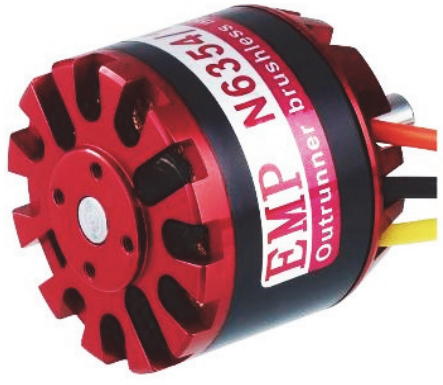

Fig. 4. Electric motor EMP N6354/1.

Table 1. Technical specification of the EMP engine N6354/13.

\begin{tabular}{|l|c|}
\hline \multicolumn{1}{|c|}{ Parameter } & Value \\
\hline Power [W] & 2500 \\
\hline Engine shaft speed/1 V [rpm] & 250 \\
\hline No-load current [A] & 1.7 \\
\hline Internal resistance [V] & 53 \\
\hline Diameter [mm] & 63.4 \\
\hline Length [mm] & 57 \\
\hline Output shaft diameter [mm] & 10 \\
\hline Engine weight [g] & 558 \\
\hline
\end{tabular}

A twin-blade propeller with a diameter of $457 \mathrm{~mm}$ and a pitch of $254 \mathrm{~mm}$ made of plastic were selected for determining the operating characteristics of the electric motor.

To power the electric motor two lithium-polymer batteries were used, $30 \mathrm{C} 6000 \mathrm{mAh} 18,5 \mathrm{~V}$, connected in series. These types of batteries are characterized by: low mass, high operating voltage, low capacity loss at negative temperatures. During the tests, the electric motor and shaft speed controller used the same power source. This solution is the most beneficial considering the application of the propulsion assembly on the airplane, as the use of one power source does not increase substantially the entire weight of the power supply. Therefore, an arrangement of the test bench was adopted so as to reflect as much as possible the energy consumption by the device responsible for motor control.

A two-stroke boxer engine was second object (Fig. 5). The engine was manufactured by Zhejiang RCGF Model \& Engine and marked RCGF 30. The main advantage of the selected engine is the large power to mass ratio. The technical specifications of the engine are shown in Table 2.

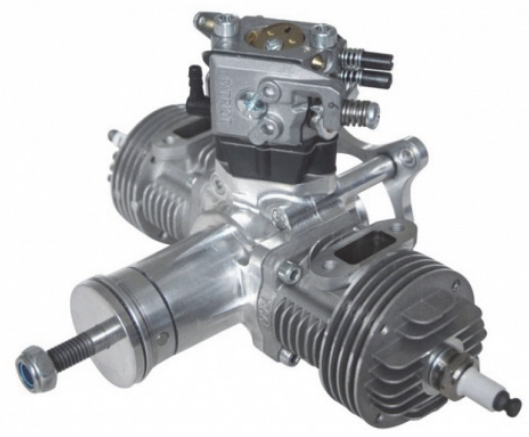

Fig. 5. Combustion engine RCGF 30. 
Table 2. Technical specification of the RCGF 30.

\begin{tabular}{|l|c|}
\hline \multicolumn{1}{|c|}{ Parameter } & Value \\
\hline Engine capacity $\left[\mathrm{cm}^{3}\right]$ & 30 \\
\hline Output power [W] & 2800 \\
\hline Useful engine speed [rpm] & $1500-7000$ \\
\hline Ignition system & $\begin{array}{c}\text { DC-CDI, } \\
\text { supply voltage 4,8-6 V }\end{array}$ \\
\hline Fuel system & $\begin{array}{c}\text { Unleaded fuel + synthetic } \\
\text { oil (30:1) }\end{array}$ \\
\hline Weight [g] & 970 \\
\hline
\end{tabular}

The operating characteristics of the internal combustion engine were determined using a two-blade carbon propeller of the same diameter and pitch of the propeller as in the case of an electric motor propeller.

A specially designed test bench (Fig. 6) was used to determine the characteristics of the motors. During the tests the following parameters were recorded:

- thrust force,

- shearing force,

- engine shaft speed,

- electric current,

- input power of electric motor,

- fuel consumption.

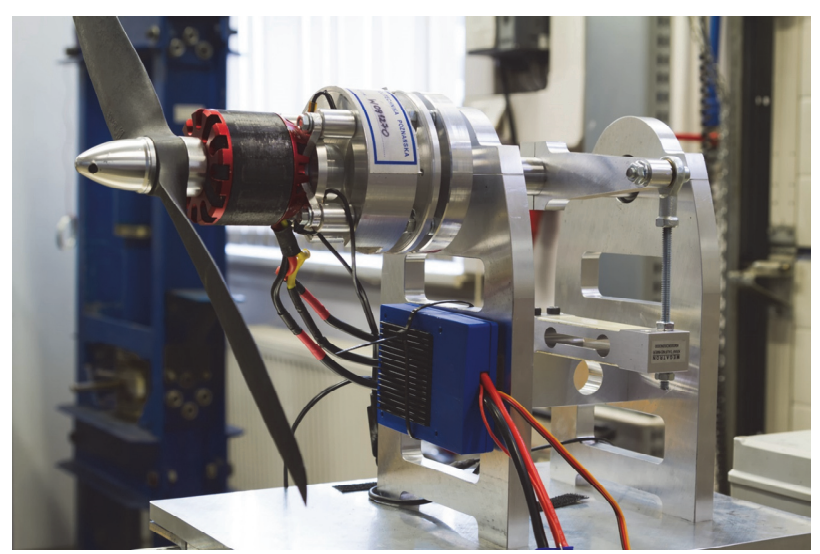

Fig. 6. View of the test bench.

The test bench (Fig. 7) was equipped with two strain gauges capable of measuring the thrust force and the shearing force. Measurement of the electric motor speed was carried out with a sensor using the optical method. The test bench featuring the universal method of mounting the engines makes it possible to conduct tests of other models of electric motors intended for the model aircraft. In order to visualize the results, the sensors used during the measurements were connected to a Wobit programmable indicators MD150T (Fig. 8). These indicators are designed to work with strain gauges for measuring force, enabling the measurements with a resolution of $0.001 \%$.

An optical method was used to measure the engine shaft speed of the electric motor. The engine shaft speed for combustion engine was measured by Hall sensor which supplied by the manufacturer.

The fuel consumption of the combustion engine was measured using the volumetric method.

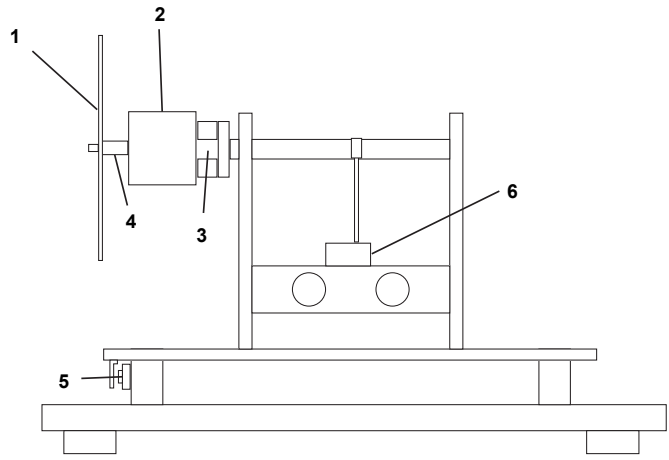

Fig. 7. Schematic of the test bench: 1 - tested airscrew, 2 - electric motor/combustion engine, 3 - shaft speed sensor (electric motor) , 4 - shaft speed sensor (combustion engine), 5 - thrust force sensor, 6 - shearing force sensor.

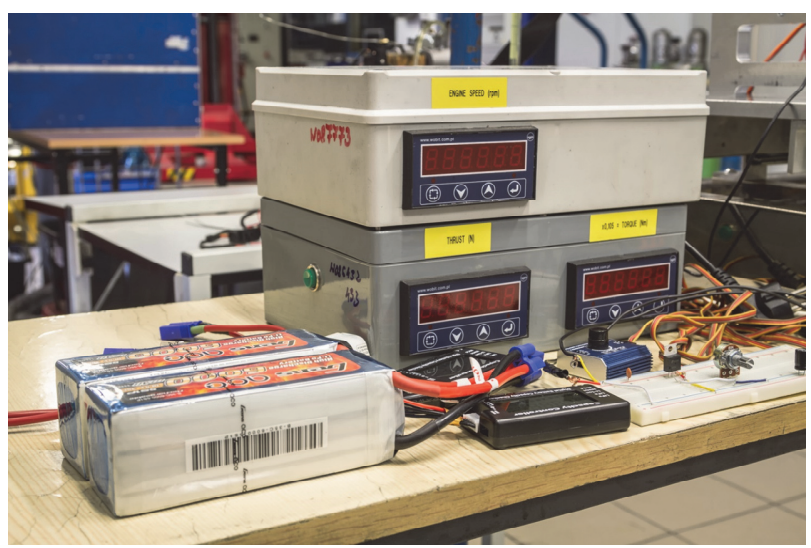

Fig. 8. View of the data loggers.

The research was divided into two parts. The first part of this study concerned measurements for an electric motor that was conducted for thrust force ranging from $10 \mathrm{~N}$ to $50 \mathrm{~N}$. The data obtained out during the measurements was used to determine operating characteristics of the airscrew propulsion. On the basis of the obtained results were compared properties of the airscrews cooperating with a particular type of engine installed on the testing bench. Measurement of transverse forces enabled the determination of torque, which, together with the measured engine speed, was used to determine the output power of the engine.

The second part of the study included the measurements for combustion engine. Measurements were conducted for thrust force ranging from $30 \mathrm{~N}$ to 70 $\mathrm{N}$. The assumed range of tested parameters was conditioned by the possibility of ensuring stabilized operation of the internal combustion engine at the test bench. As in the first part, the shearing force was used to determine the torque generated by the airscrew blades.

\section{Analysis of the measurement results}

The conducted measurements and calculations are presented in the form of dependence of the thrust force, transverse force, electric current, input power and output power on the electric motor shaft speed, and the efficiency as a torque function (Figures 9-12). 


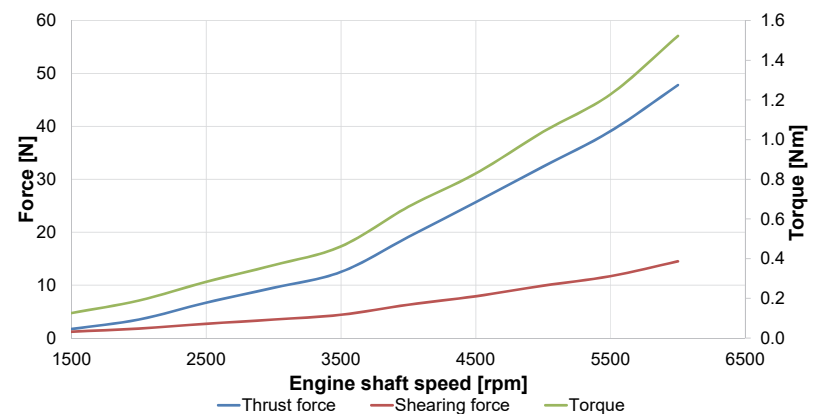

Fig. 9. Thrust, shearing force and torque as the engine shaft speed function.

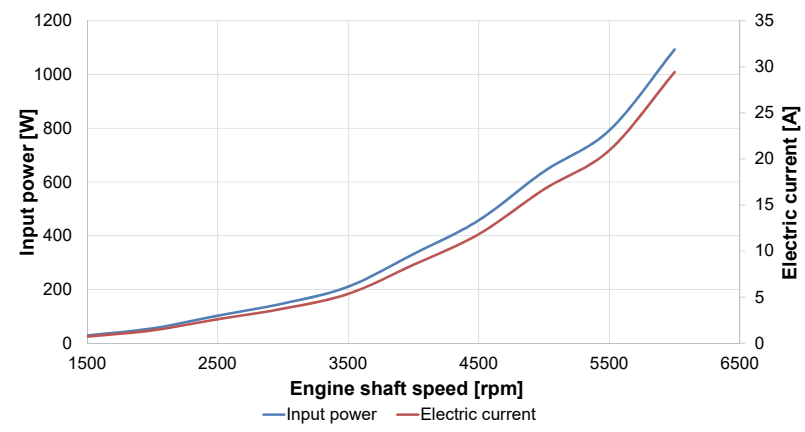

Fig. 10. Input power and electric current as the engine shaft speed function.

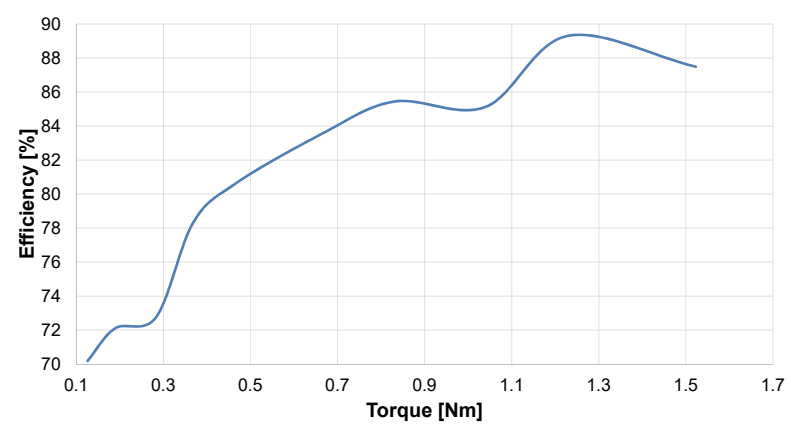

Fig. 11. Electrical motor efficiency as the torque function.

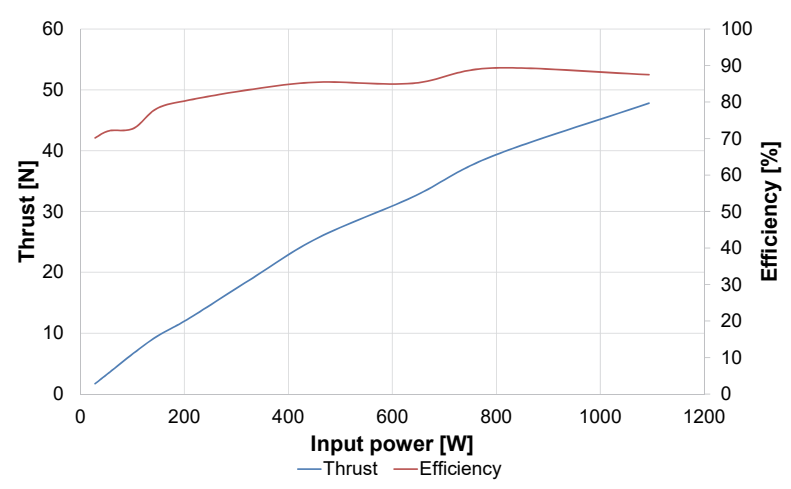

Fig. 12. Thrust as the input power function.

The thrust force is a component of aerodynamic forces generated on the airscrew blades. Obtaining the assumed values of the thrust force required different values of engine shaft speed. For a maximum engine speed of $6000 \mathrm{rpm}$, a thrust of $47.8 \mathrm{~N}$ was achieved using a two-blade propeller. For a maximum engine speed of $6000 \mathrm{rpm}$, a thrust of $47.8 \mathrm{~N}$ was achieved using a twin-blade propeller. For steady-state research, higher thrust and shearing force were obtained. During the measurement, torque was increased with increasing engine shaft speed. The torque curve as the engine shaft speed function allows to determine the impact of airscrew on the torque value. Depending on the parameters of the airscrew, it acts with greater or lesser resistance to the engine. During the tests, the maximum torque reached $1.5 \mathrm{Nm}$. The obtained thrust, shearing force and torque as the engine shaft speed based on rotational speed are similar to the exponential growth.

By analyzing the obtained input power values depending on the speed of the motor shaft, the highest energy consumption can be observed for electric motor, setting engine shaft speed of $6000 \mathrm{rpm}$, where the measured power was $1093.4 \mathrm{~W}$ and the current was 29.44 A. The energy consumed by motor from battery is due to the geometry of the airscrew, i.e. the coefficient of aerodynamic drag on the airscrew blades. Based on characteristics of the input and output power as a function of the speed differences can be observed between the electrical power supply of the motor, which is higher than the mechanical power obtained at the engine output. The output power of the motor according to the model depends on the torque and the speed of the motor shaft.

As the propulsive efficiency of the airscrew during the engine test in stationary conditions or at a very high flying speed has the value of zero, the propulsive efficiency of the engine was shown in relation to the torque. The obtained values of propulsive efficiency range from 70 to $89 \%$. Lower values of propulsive efficiency were determined for low motor shaft speed settings on the controller. Operation of the engine at such parameters is associated with lower current intensity, below the high efficiency of the engine. The highest efficiency, reaching $89 \%$.

As shown in Figure 12, the dependence of the input power on the produced thrust is an important information at the propeller selection stage. In the case of selecting a airscrew of equal diameter but larger pitch, it is possible to increase the power required to achieve the specified thrust. Also significant is the change in the efficiency curve of the electric motor depending on the type of airscrew mounted.

The conducted measurements and calculations in second part of the research are presented (Fig. 13-16) in the form of dependence of the thrust force, torque, output power, fuel consumption on the combustion engine shaft speed.

During the test, the maximum thrust $(70 \mathrm{~N})$ was obtained, for the engine crankshaft rotational speed of $6700 \mathrm{rpm}$.

Figure 14 shows the torque dependence on the rotational speed of the motor shaft. Analyzing the obtained characteristic curve, an increase in torque can be observed with the increase of the rotational speed of the shaft of the internal combustion engine. The diagram presenting dependence of the transverse force on the speed makes it possible to assess the force with which an 
airscrew influences the engine housing. The highest torque value of $2.2 \mathrm{Nm}$ was achieved at maximum engine settings. Characteristic of torque to the internal combustion engine as the engine shaft speed function is similar to the exponential growth.

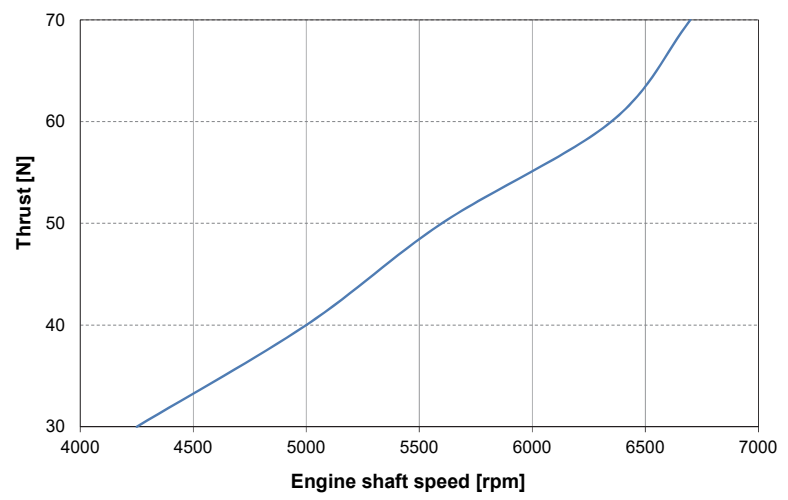

Fig. 13. Thrust as the engine shaft speed function.

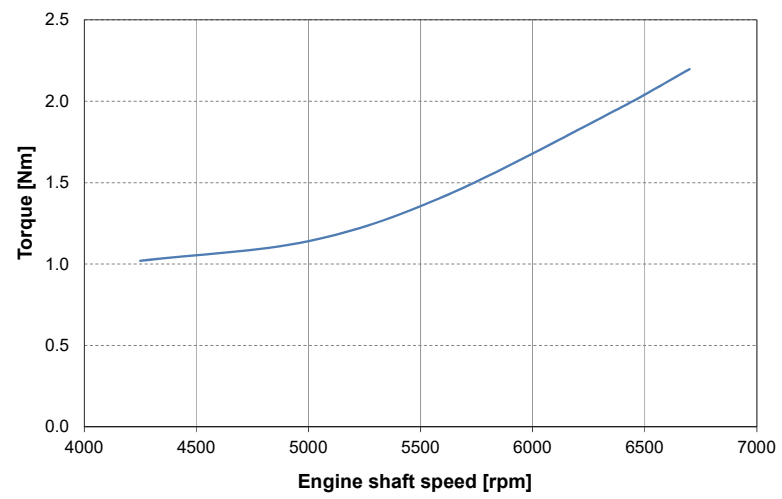

Fig. 14. Torque as the engine shaft speed function.

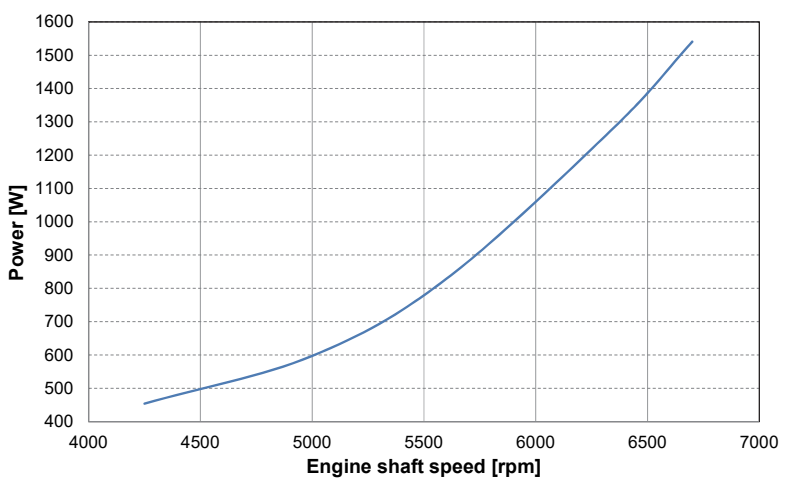

Fig. 15. Engine power as the engine shaft speed function.

The highest output power of the engine was obtained with a maximum shaft speed tested and a torque equal to $2.2 \mathrm{Nm}$. The value of useful power is closely related to the generated torque and engine shaft speed. The airsrcew propulsion in steady conditions, the power produced by the engine must balance the power absorbed by the airscrew. In this case, the geometry of the airscrew used and the flight conditions of the aircraft are of great importance.

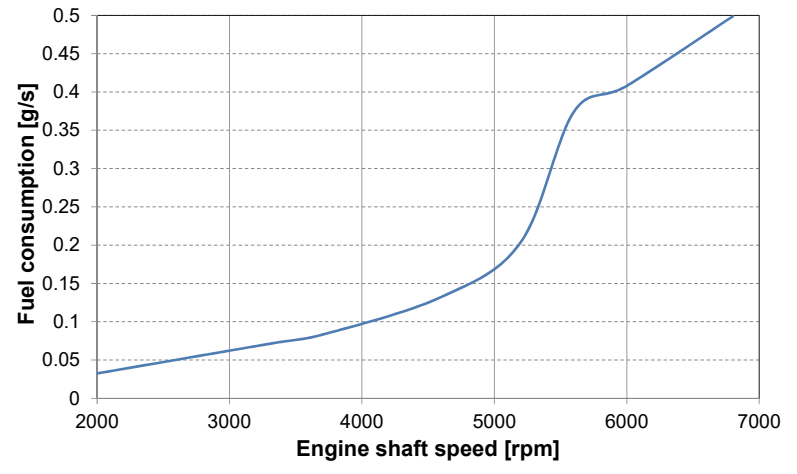

Fig. 16. Fuel consumption as the engine shaft speed function.

By analyzing the fuel consumption per second an increase of this parameter along with the increase of the rotational speed can be observed. The highest fuel consumption $(0.5 \mathrm{~g} / \mathrm{s})$ was achieved, at the engine shaft speed of $6700 \mathrm{rpm}$ and a torque of $2.2 \mathrm{Nm}$.

\section{Summary}

The dynamic development of air transport is a significant factor in the economic development of the world. However, it also generates an increase in nuisance and problems of particular relevance specifically in the local scale, especially near the airports. The source of problems are jet engines of passenger aircraft as well as General Aviation aircraft. However, for the last years a new type of aircraft started being used: UAV (Unmanned Aerial Vehicle). They are usually associated with military applications, but they are also used in civilian environments. In most cases the weight of the units used is in the range of 3 to about $15 \mathrm{~kg}$. Depending on their size and destination, different types of propulsion systems are used. Because of its small mass, most UAVs are powered by electric motors up to $6 \mathrm{~kg}$. In the ecological aspect, unmanned aerial vehicles has a small flying time compared to civil and military aircrafts. Therefore, statistically treated, the unnamed aerial vehicle are not a threat. Exhaust emission of this objects is incomparably lower.

Another aspect of the impact of unmanned aerial vehicle engines on the environment is the noise emission. Due to the low popularity and high independence of this type of unit - there is no platform certification for sports and leisure use - designers are not obliged to adhere to any standards. For military purposes, it is important that the UAV is characterized by the lowest noise emission. In conclusion - the emission of noise from the UAV is not an environment nuisance.

The operation of unmanned aerial vehicles can significantly reduce the global emissions and noise from air transport. In military operation, unmanned aerial vehicles can be particularly useful in tactical identification or direct recognition of a combat field. The use of the UAV possible to limit the flying time of multipurpose airplanes typically characterized by high emissions and noise levels and increased radar and thermal detection. The costs of buying and using 
unmanned aerial vehicles are often incomparably lower, and the operation is much simpler and cheaper.

The tests conducted make it possible to specify the scope of required electric power needed to power the airscrew propulsion. Determination of the scope of power consumed by the electric motor powering the airscrew is one of the stages of the research leading to the construction of a hybrid drive system for the aircraft (Fig. 17).

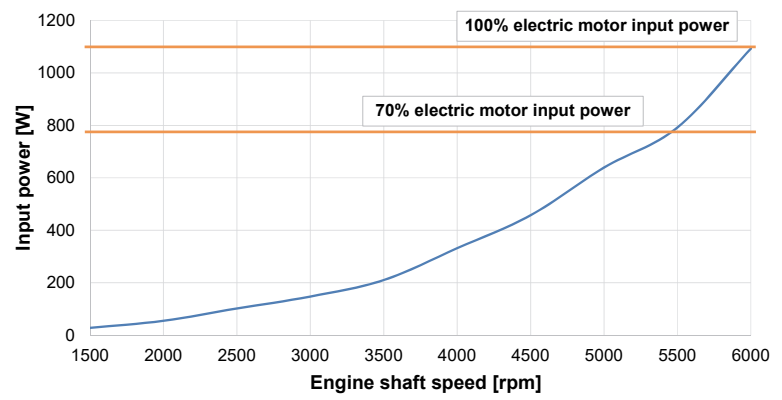

Fig. 17. Input power consumption of electric motor.

On the basis of the conducted measurements, it is possible to formulate the following assumptions:

- $\quad$ supply voltage of electric motor $U_{\mathrm{dc}}=32-40 \mathrm{~V}$,

- the energy delivered to the airscrew propulsion should ensure its operation with the maximum power of $1100 \mathrm{~W}$ to obtain the thrust force of $50 \mathrm{~N}$,

- the power source should allow the maintenance of a constant electric power of $770 \mathrm{~W}$, assuming that the power needed for flying comprises $70 \%$ of the maximum power,

- battery discharge protection below $80 \%$ of rated voltage.

On the basis of these requirements, it is possible to propose alternative propulsion system for the unnamed aerial vehicle which is a combination of electric motor and internal combustion engine. Hybrid drive systems shown in Figures 18 and 19 were designed in a CAD software.

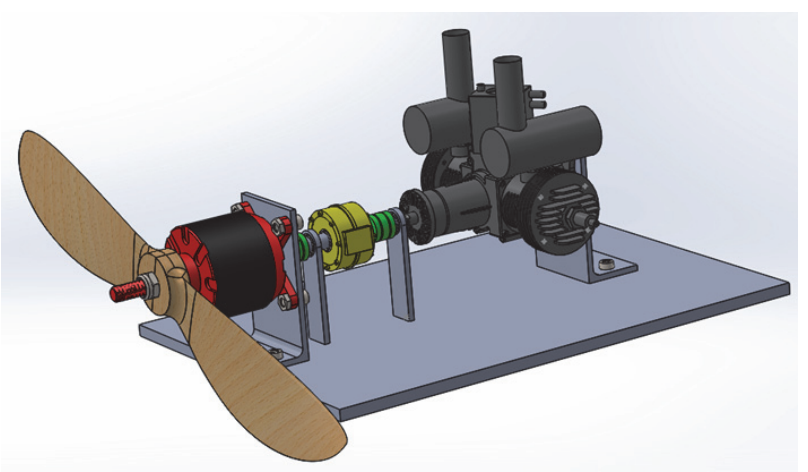

Fig. 18. Hybrid Drive System no. 1.

The configuration used in the hybrid drive system 1 assumes the use of an electric motor as the primary propeller unit. The combustion engine in this connection is an auxiliary power unit driving the airscrew when the electric motor is in generator mode. The use of an electromagnetic clutch allows the airscrew to be driven only by an electric motor powered by the energy stored in the batteries.

The hybrid drive system 2 has a configuration in which the combustion engine is the main drive unit. In this case, the engine should be operation in range of engine shaft speed corresponding to high general engine efficiency. The electric motor can act as an auxiliary unit responsible for replenishing periodic power shortages. The loading process can be accomplished during a stabilized flight profile, where the excess power of the internal combustion engine could be recovered by an electric generator operating in generator mode and converted into electric power to be supplied to the batteries.

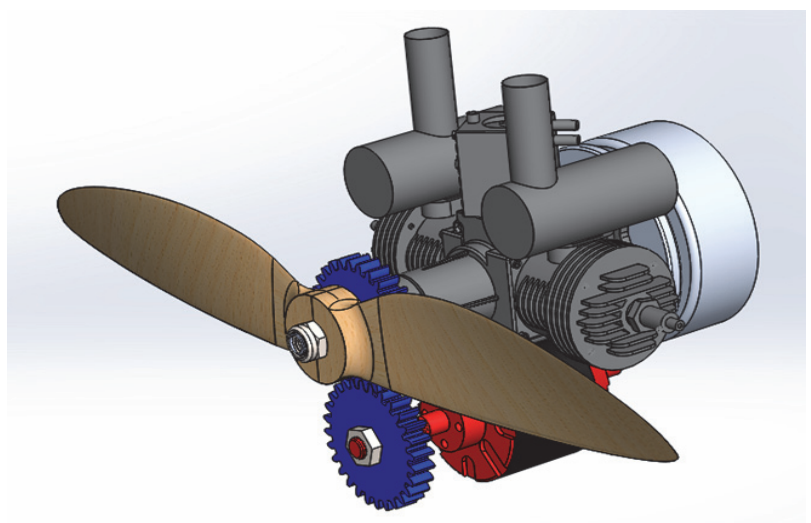

Fig. 19. Hybrid Drive System no. 2.

At the stage of constructing the hybrid drive system, special attention should be paid to such system features as:

- maximum energy efficiency,

- minimum weight and size of simplicity of the structure for ease of operation and control,

- limited ecological impact (noise level, exhaust emission).

Also important is the selection of geometric parameters of airscrew to ensure the operation of two alternate energy sources in the widest possible range of engine shaft speed.

The study presented in this article was performed within the statutory research (contract No. 05/52/DSMK/0249).

\section{References}

1. R. Charchurski, Journal of KONES Powertrain and Transport 14 (2007)

2. I. Colomina, P. Molina, Journal of Photogrammetry and Remote Sensing 92, 79-97 (2014)

3. Z. Czyż, M. Gęca, Logistyka 5, 2015

4. P. Sawicki, Archiwum Fotogrametrii, Kartografii i Teledetekcji 23 (2012)

5. Z. Juda, M. Noga, IOP Conference Series Materials Science and Engineering 148, UNSP 
$012042 \quad$ (2016), DOI: $\quad 10.1088 / 1757-$ $899 X / 148 / 1 / 012042$

6. Unmanned Aircraft Systems Roadmap 2005-2030 (Department of Defense USA, 2005)

7. Consumer Drones by the Numbers in 2017 and Beyond (www.newsledge.com, 2017)

8. The Consumer Drone Market: Trend Analysis (emberify.com, 2016)

9. The numbers behind the worldwide trade in drones (www.theguardian.com, 2015)

10. J. Merkisz, J. Markowski, J. Pielecha, WIT Transactions on Ecology and the Environment 174, 219-230 (2013), DOI: 10.2495/AIR130191

11. J.Y. Hung, L.F. Gonzalez, Progress in Aerospace Sciences 51, 1-17 (2012)

12. D. Taler, A. Cebula, Inzynieria Chemiczna i Procesowa 25, 2331-2342 (2004)

13. M. Ehsani, Y. Gao, S.E. Gay, A. Emadi, Fundamentals, Theory, and Design (CRC Press, 2005)

14. I. Husain, Electric and Hybrid Vehicles Design Fundamentals (CRC Press, 2003)

15. J. Lieh, E. Spahr, A. Behbahani, J. Hoying, 47th Joint Propulsion Conference \& Exhibit

16. J. Xu, APAS R\&D Center (Hong Kong, 2007)

17. B. Uragun, I. Tansel, International Conference On Unmanned Aircraft Systems (Orlando, 2014) 